\title{
THE EFFECT OF DIFFERENT AFFORESTATION TREE SPECIES ON PLANT DIVERSITY AFTER 50 YEARS ON MOUNT TAI, CHINA
}

\author{
ZHOU, J. ${ }^{1}-$ GAO, Y. $.^{2,3^{*}}-$ WANG, Y. ${ }^{2}-$ ZHAO, Y. J. ${ }^{4}$ \\ ${ }^{1}$ School of Life Sciences, Qufu Normal University, Jining 273 165, China \\ (e-mail: jingzhou-2004@163.com) \\ ${ }^{2}$ Shandong Provincial Key Laboratory of Water and Soil Conservation and Environmental \\ Protection, College of Resources and Environment, Linyi University, Linyi 276 005, China \\ (e-mail:wangyunsd@163.com) \\ ${ }^{3}$ Linyi Scientific Exploration Laboratory, Linyi 276 037, China \\ ${ }^{4}$ College of Agriculture and Forestry, Linyi University, Linyi 276005, China \\ (e-mail: zhaoyanjie1882@126.com) \\ *Corresponding author \\ e-mail:gaoyuan1182@tom.com \\ (Received $4^{\text {th }}$ Jun 2021; accepted $3^{\text {rd }}$ Sep 2021)
}

\begin{abstract}
The degree of forest vegetation restoration and reconstruction and the impact of different afforestation tree species on plant diversity in Mount Tai, China were evaluated. We selected 6 kinds of 50-year-old plantations along Tianwai village, Hongmen, Tianzhu peak and Taohuayuan lines. The results show that: 1) Robinia pseudoacacia plantation has significantly lower tree layer richness, Shannon-Wiener diversity and Simpson diversity than other plantations; Pinus tabulaeformis and larch tree plantations have significantly lower shrub layer Shannon -Wiener and Simpson diversity than other plantations, Pinus tabulaeformis and Pinus densiflora have significantly lower Pielou evenness than the other four plantations; Pinus tabulaeformis plantation and Platycladus orientalis plantation have significantly lower herb layer richness than the other four plantations, while Pinus tabulaeformis plantation has significantly lower Shannon-Wiener diversity and Simpson diversity than the other five plantations. 2) Species richness, Shannon-Wiener diversity and Simpson diversity of tree and shrub layers are all presented from highest to lowest in the following order: Mount Meng > Mount Tai > Mount Yi, while Mount Tai plantation has the highest herb layer species richness, Shannon-Wiener diversity and Simpson diversity. These results provide basis for the regulation and prediction of regional forest vegetation restoration and reconstruction in the future.
\end{abstract}

Keywords: vegetation restoration, plant diversity, shrub layer, 50-year-old plantations, Mount Tai, plantation, plant diversity, soil, 50-year Forest Establishment

\section{Introduction}

Biodiversity provides the basis for maintaining the stability of ecosystem structure and function (Wang et al., 2016), which represents one core issue in plant ecology (Kazakou et al., 2008). Changes in species diversity in the process of vegetation restoration reflect the degree of vegetation restoration, which is also a result of the combined effects of ecological processes such as community environmental evolution, population intrusion and diffusion (Kapás et al., 2020), and competition. Excessive studies have confirmed that plantation forests can effectively prevent land degradation and promote vegetation restoration (Depauw et al., 2019), but different initial afforestation tree species will lead to significantly different plant community structures and species diversity of plantation 
forests (Togonidze and Akhalkatsi, 2015). Studies have shown that the use of exotic species for afforestation will weaken the natural restoration of native plants and reduce plant diversity of the community (Xue et al., 2016). However, studies also found that use of exotic species for afforestation can contribute to biodiversity conservation and protect successional tree species in the later stage, which will eventually be restored to native zonal vegetation and exotic species will be withdrawn (Assandri et al., 2016). Plantation forests are superior to enclosed forests in terms of biodiversity conservation potential, and its species of harmful plants are also fewer compared to the latter (Huang et al., 2015). To maintain stability of plantation forest ecosystem and maximize its functions, species diversity research after vegetation restoration is particularly important. There is a need to evaluate the vegetation restoration and reconstruction processes and effects based on the principle of biodiversity (Lindenmayer et al., 2018). For plantation forest more than 50 years old, dynamics research on vegetation restoration and reconstruction is ever more urgent due to the scarcity of samples (Chi et al., 2004; Fan et al., 2008; Gao et al., 2011).

Due to its complex and diverse ecological environmental conditions, the mountainous region has become a germplasm bank for species survival, reproduction and preservation (Tian and Li, 2012). Mount Tai, standing on the North China Plain, is the highest mountain in Shandong. Rich in wild plant resources, it is the mountain with the most diverse vegetation, and the highest number of endemic plant species in Shandong Province (Su et al., 2018), which is a dual heritage of world culture and nature, World Geopark, National Key Cultural Relics Protection Unit, National Key Scenic Spot and National 5A Tourist Attraction. The research on Mount Tai vegetation began with the front forest vegetation investigation of Mount Tai by the East China Forestry Investigation Team in 1950, the Mount Tai Vegetation Investigation Team of Botanical Geography Training Class of East China Normal University in 1956, and the Geobotany Investigation Team of Shandong University in 1957 (Kyohou, 1958). After more than 60 years of inheritance, there have been studies on plant diversity in some forest types (Chen et al., 2019) and some forest farms (Kuswanda et al., 2019).

Based on previous studies, this paper intends to conduct a field investigation on 50 -year restoration and reconstruction of six main afforestation tree species in Mount Tai, evaluate the status and extent of forest vegetation restoration and reconstruction, and examine the impact of different afforestation tree species on plant diversity, thus providing a basis for the regulation and prediction of regional forest vegetation restoration and reconstruction in the future.

\section{Materials and methods}

\section{Overview of the sample plot}

Mount Tai is located in the middle of Shandong, China, with geographic coordinates of $36^{\circ} 05^{\prime}-36^{\circ} 15^{\prime} \mathrm{N}, 117^{\circ} 05^{\prime}-117^{\circ} 24^{\prime} \mathrm{E}$, covering an area of $426 \mathrm{~km}^{2}$. The main peak, Yuhuangding, with an altitude of $1545 \mathrm{~m}$, is the highest peak in Shandong. The mountain is mainly composed of complex rock-crystalline gneiss and metamorphic granite, with a small amount of limestone and sandy shale. The soil types are mainly brown soil, ordinary acid brown soil, mountain dark brown soil and mountain shrubby meadow soil, with ordinary acid brown soil as the most common type. The climate is warm-temperate continental monsoon climate with four distinct seasons and sufficient sunlight. The annual average temperature is about $5.3^{\circ} \mathrm{C}$ at the mountain top and $12.8^{\circ} \mathrm{C}$ at the mountain foot. The average annual rainfall is about $1125 \mathrm{~mm}$ at the mountain top, and $600 \mathrm{~mm}$ at 
the mountain foot. The forest coverage rate is about $81.5 \%$, and the main vegetation is Pinus tabuliformis forest, Platycladus orientalis forest, Pinus densiflora forest, Pinus thunbergii forest, Quercus acutissima forest, Robinia pseudoacacia forest and Quercus variabilis forest (Fu et al., 2009; Ma et al., 2010; Zhang et al., 2011). The map of the location of the sampling site was shown in Figure S1. The phenological differences between the studied species were shown in Table S1. We measured soil nutrients and the data was shown in Table 1. And soil nutrient detection methods refer to Donald (2020).

Table 1. Soil nutrients in sample plots

\begin{tabular}{l|c|c|c|c|c|c|c}
\hline & $\begin{array}{c}\text { Organic } \\
\text { matter } \\
\mathbf{g} \cdot \mathbf{k g}^{-1}\end{array}$ & $\begin{array}{c}\text { Total } \\
\text { nitrogen } \\
\mathbf{g} \cdot \mathbf{k g}^{-1}\end{array}$ & $\begin{array}{c}\text { Total } \\
\mathbf{p h o s p h o r u s} \\
\mathbf{g} \cdot \mathbf{k g}^{-1}\end{array}$ & $\begin{array}{c}\text { Total } \\
\text { potassium } \\
\mathbf{g} \cdot \mathbf{k g}^{-1}\end{array}$ & $\begin{array}{c}\text { Hydrolytic } \\
\text { nitrogen } \\
\mathbf{m g} \cdot \mathbf{k g}^{-1}\end{array}$ & $\begin{array}{c}\text { Available } \\
\mathbf{p h o s p h o r u s} \\
\mathbf{m g} \cdot \mathbf{k g}^{-1}\end{array}$ & $\begin{array}{c}\text { Available } \\
\mathbf{p o t a s s i u m} \\
\mathbf{m g} \cdot \mathbf{k g}^{-1}\end{array}$ \\
\hline PT forest & $81.0 \pm 11.3$ & $3.3 \pm 0.3$ & $1.5 \pm 0.2$ & $11.7 \pm 0.7$ & $235.9 \pm 44.8$ & $83.6 \pm 7.5$ & $70.3 \pm 7.8$ \\
PO forest & $19.7 \pm 6.1$ & $1.1 \pm 0.3$ & $0.5 \pm 0.1$ & $8.9 \pm 0.8$ & $87.0 \pm 27.0$ & $39.2 \pm 16.8$ & $59.8 \pm 9.7$ \\
RP forest & $37.3 \pm 6.2$ & $2.3 \pm 0.4$ & $0.8 \pm 0.1$ & $7.7 \pm 0.5$ & $194.7 \pm 43.6$ & $32.2 \pm 7.0$ & $69.8 \pm 16.4$ \\
PD forest & $44.3 \pm 6.4$ & $2.3 \pm 0.2$ & $1.3 \pm 0.1$ & $12.2 \pm 0.9$ & $176.2 \pm 35.7$ & $60.8 \pm 10.8$ & $79.4 \pm 8.0$ \\
LK forest & $72.9 \pm 7.5$ & $4.0 \pm 0.2$ & $1.8 \pm 0.1$ & $10.2 \pm 0.6$ & $528.5 \pm 207.2$ & $81.4 \pm 2.7$ & $92.9 \pm 22.2$ \\
PA forest & $35.7 \pm 2.9$ & $2.1 \pm 0.2$ & $0.9 \pm 0.2$ & $3.8 \pm 0.5$ & $190.9 \pm 24.0$ & $27.8 \pm 5.6$ & $69.0 \pm 10.7$ \\
\hline
\end{tabular}

PT forest $=$ Pinus tabulaeformis forest, PO forest $=$ Platycladus orientalis forest, RP forest $=$ Robinia pseudoacacia forest, PD forest $=$ Pinus densiflora forest, LK forest $=$ Larix kaempferi forest PA forest $=$ Pinus armandii Franch. forest

\section{Field investigation}

The field investigation covered Tianwai Village route, Hongmen route, Tianzhu Peak route and Taohuayuan route. 50-year-old middle-aged forest was selected as the sample plot, and typical sampling method was taken for the forest investigation (Fang et al., 2004; Yu et al., 2009). A total of 42 sample plots were set up in the field, with a dimension of $30 \mathrm{~m} \times 20 \mathrm{~m}$. The selected sample plots are neat and can represent basic characteristics of the community.

The community level is divided into tree layer, shrub layer and herb layer for hierarchical statistics. According to investigation specifications for plant species diversity in mountainous areas (Fang et al., 2004) and method specifications for the inventory of plant communities (Yu et al., 2009), statistical specifications of the plot stratification are decided as: tree layer, $30 \mathrm{~m} \times 20 \mathrm{~m}$; shrub layer, $15 \mathrm{~m} \times 15 \mathrm{~m}$, located at the center of the sample plot, 1; herb layer, $1 \mathrm{~m} \times 1 \mathrm{~m}$, located at the four corners of the sample plot, 4 . In tree layer measurement, record species and numbers of all woody plants with $(D B H) \geq 5 \mathrm{~cm}$ and $\mathrm{DBH}$ of each wood; in shrub layer measurement, record species, numbers of all woody plants with $\mathrm{DBH}<5 \mathrm{~cm}$ and DBH of each wood, including arbor seedlings, saplings and woody vines.

\section{Data processing}

Four general diversity indexes are selected for calculation and analysis of plant diversity (Fang et al., 2004; Yu et al., 2009): Richness Index (S, Equation 1), ShannonWiener Diversity Index $(H$, Equation 2$)$, Simpson Diversity Index $(P$, Equation 3$)$ and Pielou Evenness Index ( $E$, Equation 4$)$. The calculation formulas are: 
$S=$ plant species in the sample plot

$$
\begin{gathered}
H=-\sum_{i=1}^{S} P_{i} \ln P_{i} \\
P=1-\sum_{i=1}^{S} P_{i}^{2} \\
E=H / \ln S
\end{gathered}
$$

where, $P_{i}$ is the ratio of the importance value of the ${ }_{i}$-th species to the total importance value of all species in the sample plot, importance value of shrub layer $=$ (relative significance + relative density + relative frequency) $/ 3$, and importance value of herb layer $=($ relative height + relative density + relative frequency $) / 3$.

\section{Statistical analysis}

The differences in plant diversity between forest types are analyzed by single factor method and $\mathrm{T}$ test. The inter-layer and intra-layer plant diversity correlation is interpreted by principal component analysis. Data analysis and chart production are completed using SPSS 17.0 and Excel 2003.

\section{Results}

Species diversity of six plantation forests in Mount Tai after 50 years of establishment Species diversity of tree layer

Tree Species detected in the individual plots were shown in Table S2. Tree layer plant richness index, Shannon-Wiener diversity index, and Simpson diversity index present relatively consistent characteristics. That is, Robinia pseudoacacia plantation has significantly lower value than the other five plantation forests $(P<0.05)$, while Pinus tabulaeformis plantation, Platycladus orientalis plantation, Pinus densiflora plantation, Pinus armandi plantation and larch tree plantation are not significantly different from each other (Figure 1A1-Figure 1A3). There is no significant difference in Pielou evenness index of the 6 plantations in Mount Tai (Figure 1A4).

\section{Species diversity of shrub layer}

Shrub layer plant richness index is not significantly different among the six plantations (Figure 1B1). Pinus tabulaeformis plantation and larch tree plantation have significantly lower Shannon-Wiener and Simpson diversity indexes than the other four species $(P<0.05)$, Platycladus orientalis plantation, Robinia pseudoacacia plantation, Pinus densiflora plantation and Pinus armandi plantation are not significantly different from each other (Figure 1B2-Figure 1B3). Pinus tabuliformis plantation and Pinus densiflora plantation have significantly lower Pielou evenness index than the other four plantations $(P<0.05)$. Platycladus orientalis plantation, Robinia pseudoacacia plantation, Pinus armandi plantation and larch tree plantation are not significantly different from each other (Figure 1B4). 

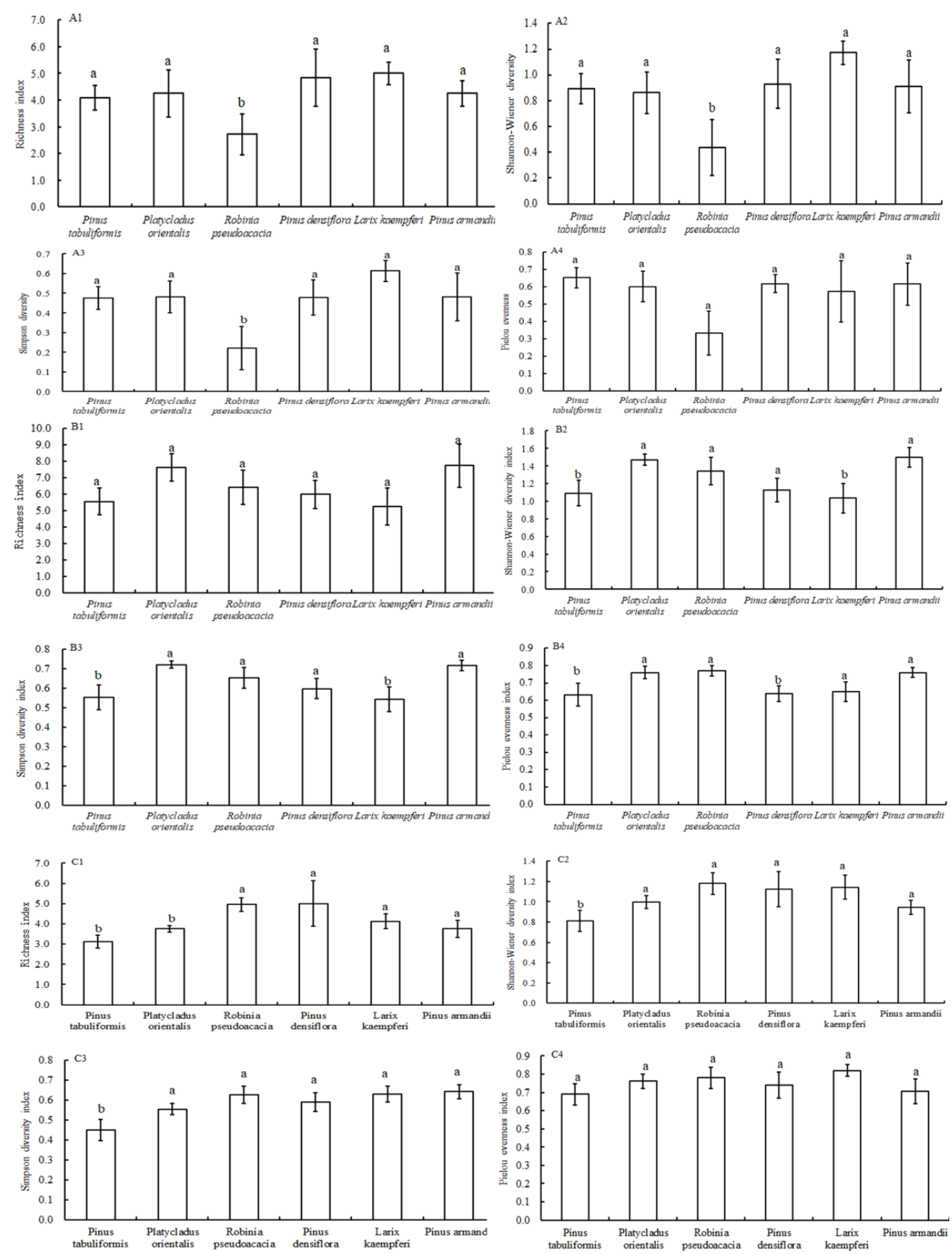

Figure 1. The richness index, Shannon-Wiener diversity index, Simpson diversity index and Pielou evenness index of the tree layer (A1-A4), shrub layer (B1-B4) and herb layer (C1-C4) of the 6 main plantations in Mount Tai (Mean \pm standard error) Different lowercase letters indicate significant differences among plantations $(P<0.05)$

\section{Species diversity of herb layer}

In herb layer, Pinus tabulaeformis plantation and Platycladus orientalis plantation have significantly lower richness index than the other four plantations $(P<0.05)$, while Robinia pseudoacacia plantation, Pinus densiflora plantation, Pinus armandi plantation 
and larch tree plantation are not significantly different from each other (Figure 1C1). Pinus tabulaeformis plantation has significantly lower Shannon-Wiener and Simpson diversity indexes than the other five plantations $(P<0.05)$, Platycladus orientalis plantation, Robinia pseudoacacia plantation, Pinus densiflora plantation, Pinus armandi plantation and larch tree plantation are not significantly different from each other (Figure 1C2-Figure 1C3). There is no significant difference in Pielou evenness index between the 6 plantations in Mount Tai (Figure 1C4).

\section{Correlation analysis of tree, shrub and herb species diversity}

The four inter-layer diversity indexes of tree layer, shrub layer and herb layer of Mount Tai plantations are all significantly positively correlated and inter-layer richness index, Shannon-Wiener diversity index and Simpson diversity index show significant positive correlation between shrub layer and herb layer (Table 2).

Table 2. Correlation of species diversity of tree, shrub and herb in the Taishan plantation

\begin{tabular}{c|cccccccccccc}
\hline & $\mathrm{T}-\mathrm{S}$ & $\mathrm{T}-\mathrm{H}$ & $\mathrm{T}-\mathrm{P}$ & $\mathrm{T}-\mathrm{E}$ & $\mathrm{S}-\mathrm{S}$ & $\mathrm{S}-\mathrm{H}$ & $\mathrm{S}-\mathrm{P}$ & $\mathrm{S}-\mathrm{E}$ & $\mathrm{H}-\mathrm{S}$ & $\mathrm{H}-\mathrm{H}$ & $\mathrm{H}-\mathrm{P}$ & $\mathrm{H}-\mathrm{E}$ \\
\hline $\mathrm{T}-\mathrm{S}$ & 1.00 & & & & & & & & & & & \\
$\mathrm{~T}-\mathrm{H}$ & $0.89^{* *}$ & 1.00 & & & & & & & & & & \\
$\mathrm{~T}-\mathrm{P}$ & $0.80^{* *}$ & $0.98^{* *}$ & 1.00 & & & & & & & & & \\
$\mathrm{~T}-\mathrm{E}$ & $0.53^{* *}$ & $0.77^{* *}$ & $0.83^{* *}$ & 1.00 & & & & & & & & \\
$\mathrm{~S}-\mathrm{S}$ & 0.15 & 0.14 & $0.12^{*}$ & 0.02 & 1.00 & & & & & & & \\
$\mathrm{~S}-\mathrm{H}$ & 0.08 & 0.08 & 0.06 & -0.06 & $0.88^{* *}$ & 1.00 & & & & & & \\
$\mathrm{~S}-\mathrm{P}$ & 0.05 & 0.08 & 0.07 & -0.02 & $0.74^{* *}$ & $0.96^{* *}$ & 1.00 & & & & & \\
$\mathrm{~S}-\mathrm{E}$ & -0.00 & 0.05 & 0.05 & -0.01 & $0.32^{*}$ & $0.68^{* *}$ & $0.81^{* *}$ & 1.00 & & & & \\
$\mathrm{H}-\mathrm{S}$ & -0.16 & -0.24 & $-0.30^{*}$ & -0.23 & $0.32^{*}$ & $0.35^{* *}$ & $0.31^{*}$ & 0.19 & 1.00 & & & \\
$\mathrm{H}-\mathrm{H}$ & 0.01 & -0.09 & -0.18 & -0.19 & $0.36^{* *}$ & $0.38^{* *}$ & $0.35^{* *}$ & 0.19 & $0.86^{* *}$ & 1.00 & & \\
$\mathrm{H}-\mathrm{P}$ & 0.01 & -0.07 & -0.16 & -0.21 & $0.35^{* *}$ & $0.36^{* *}$ & $0.33^{*}$ & 0.19 & $0.69^{* *}$ & $0.87 * *$ & 1.00 & \\
$\mathrm{H}-\mathrm{E}$ & 0.07 & -0.02 & -0.09 & -0.14 & 0.23 & 0.22 & 0.22 & 0.07 & $0.38^{* *}$ & $0.72 * *$ & $0.71^{* *}$ & 1.00 \\
\hline
\end{tabular}

$\mathrm{T}-\mathrm{S}$, tree layer richness index; T-H, tree layer Shannon-Wiener diversity index; T-P, tree layer Simpson diversity index; T-E, tree layer Pielou evenness index; S-S, shrub Layer richness index; S-H, shrub layer Shannon-Wiener diversity index; S-P, shrub layer Simpson diversity index; S-E, shrub layer Pielou evenness index; H-S, herb layer richness index; $\mathrm{H}-\mathrm{H}$, Shannon-Wiener diversity index of herb layer; $\mathrm{H}-\mathrm{P}$, Simpson diversity index of herb layer; $\mathrm{H}-\mathrm{E}$, Pielou evenness index of herb layer, *, $P<0.05$; **, $P<0.01$

\section{Differences in plant diversity between Mount Tai, Mount Meng and Mount Yi plantations}

Species richness index

The species richness indexes of tree layer and shrub layer are both presented as that of Mount Meng plantation> Mount Tai plantation> Mount Yi plantation $(p<0.05)$, while that of herb layer is presented as that of Mount Tai plantation> Mount Meng plantation $>$ Mount Yi plantation $(P<0.05)$ (Figure $2 A)$. 


\section{Shannon-Wiener diversity index}

Shannon-Wiener diversity index of tree layer and shrub layer is presented as that of Mount Meng plantation> Mount Tai plantation> Mount Yi plantation $(P<0.05)$, while the herb layer is presented as that of Mount Tai plantation $>$ Mount Yi plantation> Mount Meng plantation. Lin $(P<0.05)$ (Figure $2 B)$.
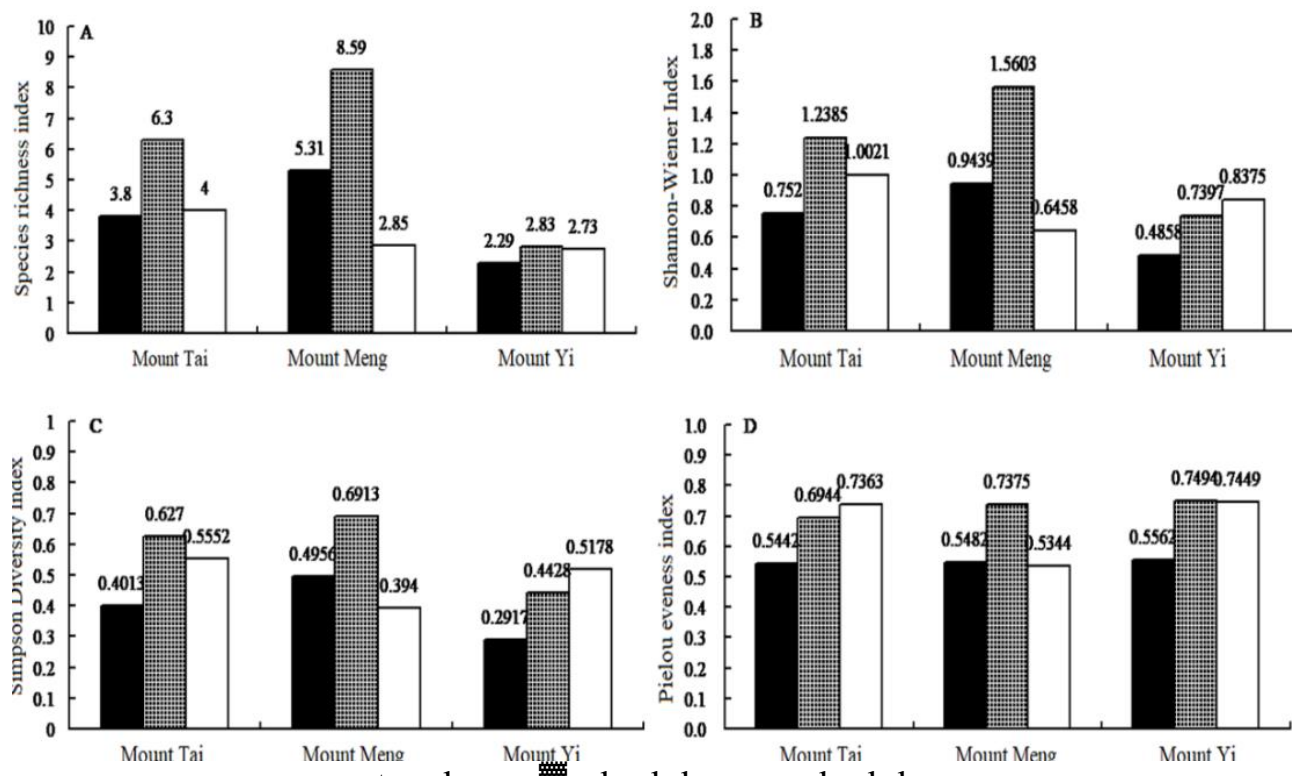

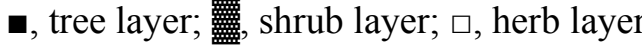

Figure 2. The abundance index (A), Shannon-Wiener diversity index (B), Simpson diversity index $(C)$, and Pielou evenness index (D) of the tree layer and shrub layer of Taishan, Mengshan and Yishan plantations and herb layer difference

\section{Simpson diversity index}

Simpson diversity index of tree layer and shrub layer is presented as that of Mount Meng plantation> Mount Tai plantation> Mount Yi plantation, while the herb layer is presented as that of Mount Tai plantation> Mount Yi plantation> Mount Meng plantation (Figure 2C).

\section{Pielou eveness index}

Pielou evenness indexes of tree layer and shrub layer are both presented as that of Mount Yi plantation> Mount Meng plantation> Mount Tai plantation, while the herb layer is presented as that of Mount Yi plantation>T Mount Tai plantation> Mount Meng plantation (Figure 2D).

\section{Discussion}

Most of the existing vegetation in Mount Tai is plantation forest after the founding of the People's Republic of China, with a few natural forests and secondary forests. The six main plantations are subjected to dual influence of vegetation evolution history and interference from human activities. The vegetation types, plant communities and species diversity are mainly affected by artificial afforestation in the early stage and tourism 
activities and natural succession in the later period. The six plantations in Mount Tai have been enclosed for 50 years. Under strict and effective local forestry management, soil and water conservation is fine, the forest coverage rate is significantly increased, plant species are significantly increased, so the forest vegetation is restored and rebuilt smoothly, but different plantations differ greatly.

Robinia pseudoacacia plantation in Mount Tai has significantly lower tree layer richness index, Shannon-Wiener diversity index and Simpson diversity index than the other five plantations. This may be due to the inhibition of Robinia pseudoacacia forest growth on the understory (Wu et al., 2017). Therefore, we should carry out thinning management for the existing stands with high canopy density in time to promote the growth of lower vegetation, reasonably allocate trees, shrubs and grasses, enrich the community hierarchy and improve the ecological function of Robinia pseudoacacia forest. Pinus tabulaeformis plantation and larch tree plantation have significantly lower shrub layer Shannon -Wiener diversity index and Simpson diversity index than the other four plantations, Pinus tabulaeformis plantation and Pinus densiflora have significantly lower Pielou evenness index than the other four plantations; Pinus tabulaeformis plantation and Platycladus orientalis plantation have significantly lower herb layer richness index than the other four plantations, while Pinus tabulaeformis plantation has significantly lower Shannon-Wiener diversity index and Simpson diversity than the other five plantations. On the whole, among the six main plantations in Mount Tai, Robinia pseudoacacia plantation has the lowest plant diversity in the tree layer, while Pinus tabulaeformis plantation has the lowest plant diversity in the shrub and herb layers. This result was inconsistent with our previous research in Mengshan mountain, which may be caused by the difference of afforestation time, geographical location, soil and climate between the two mountains (Gao et al., 2009).

The four inter-layer diversity indexes of tree layer, shrub layer and herb layer of Mount Tai plantations are all significantly positively correlated, while inter-layer richness index, Shannon-Wiener diversity index and Simpson diversity index show significant positive correlation between shrub layer and herb layer.

According to the investigation, the six main plantations in Mount Tai display sparseness within the trees and simplification of the community appearance, which may be due to the different growth habits and reproduction strategies of plants. For example, perennial forbs have strong tolerance and cushion against disturbances, while shrubs and semi-shrubs are sensitive to interference (Zheng et al., 2008; Gao, 2009). Species richness index, Shannon-Wiener diversity index and Simpson diversity index of tree layer and shrub layer are all presented as that of Mount Meng plantation> Mount Tai plantation> Mount Yi plantation, while Mount Tai plantation has the highest herb layer species richness index, Shannon-Wiener diversity index and Simpson diversity index, though it has the lowest tree layer and shrub layer Pielou evenness index. The understory shrub and herb layer vegetation generally features shade tolerance and fast growth rate, which can easily form a thick and dense evergreen understory shrub and herb layer in the forest ecosystem, thus limiting the natural regeneration of trees, and restricting forest regeneration to a certain extent (Kobayashi et al., 2010).

\section{Conclusion}

In the current study, the degree of forest vegetation restoration and reconstruction and the impact of different afforestation tree species on plant diversity in Mount Tai, China 
were evaluated. Compared with previous studies, this paper further discusses the effect of different after station tree species on plant diversity after 50 years on Mount Tai, China. Plantation in Mount Tai obviously has the function of protecting and improving soil particle and pore structure. The preservation and improvement of soil structure and function has become an indispensable prerequisite for the success of artificial afforestation in Mount Tai. Further research should focus on the differences of microbial communities and functional microorganisms in rhizosphere and bulk soil of afforestation tree species.

Funding. Funded by the Fund of Shandong Provincial Key Laboratory of Water and Soil Conservation and Environmental Protection, Linyi University [NO. STKF201906], the National Natural Science Foundation of China for Young Scholars [NO. 41807053], and National Natural Science Foundation of China [NO. 32071630].

\section{REFERENCES}

[1] Assandri, G., Bogliani, G., Pedrini, P., Brambilla, M. (2016): Land-use and bird occurrence at the urban margin: implications for planning and conservation. - North-Western Journal of Zoology 13(1): e161601.

[2] Chen, L., Han, W., Liu, D., Liu, G. (2019): How forest gaps shaped plant diversity along an elevational gradient in wolong national nature reserve? - Journal of Geographical Sciences 29(7): 1081-1097.

[3] Depauw, L., Perring, M. P., Brunet, J., Maes, S. L., Verheyen, K. (2019): Interactive effects of past land use and recent forest management on the understorey community in temperate oak forests in South Sweden. - Journal of Vegetation Science 30(5): 917-928.

[4] Donald, C., Phillimon, N., Henry, M., Felix, C. (2020): Fire alters the availability of soil nutrients and accelerates growth of Eucalyptus grandis in Zambia. - Journal of Forestry Research 31: 1637-1645.

[5] Fan, B., Sang, W. G., Li, G. Q., Liu, R. G., Chen, L. Z., Wang, K. (2008): Long-term protection effects of national reserve to forest vegetation in 4 decades: biodiversity change analysis of major forest types in Changbai Mountain Nature Reserve, China. - Science in China 10: 948.

[6] Fang, J., Shen, Z., Tang, Z., Wang, Z. (2004): The Protocol for the Survey Plan for Plant Species Diversity of China's Mountains. - Biodiversity Science 12(1): 5-9.

[7] Gao, Y. (2009): Effect of tourism on species composition in Mount Meng, Shandong Province. - World Sci-Tech Research and Development 31(4): 708-710.

[8] Gao, Y., Chen, Y., Dong, H., Hao, J., Ci, H. (2011): Vegetation and species diversity change analysis in 50 years in Tashan Mountain, Shandong Province, China. - Acta Ecologica Sinica 31(20): 5984-5991.

[9] Huang, X. R., He, F., Pang, S. L., Hou, Y. R., Lu, G. D. (2015): Understory biodiversity of plantations on karst mountains in Guangxi and its relation to environmental factors. Chinese Journal of Ecology 34(11): 3024-3033.

[10] Kapás, R., Plue, J., Kimberley, A., Cousins, S. (2020): Grazing livestock increases both vegetation and seed bank diversity in remnant and restored grasslands. - Journal of Vegetation Science 31(6): 1053-1065.

[11] Kazakou, E., Dimitrakopoulos, P. G., Baker, A., Reeves, R. D., Troumbis, A. Y. (2008): Hypotheses, mechanisms and trade-offs of tolerance and adaptation to serpentine soils: From species to ecosystem level. - Biological Reviews 83(4): 495-508.

[12] Kobayashi, T., Shimano, K., Muraoka, H. (2010): Effect of light availability on the carbon gain of beech (Fagus crenata) seedlings with reference to the density of dwarf bamboo 
(Sasa kurilensis) in an understory of Japan Sea type beech forest. - Plant Species Biology 19(1): 33-46.

[13] Kyohou, G. Y. (1958): The vegetation of Chaoyang Dong, Taishan, and its vicinity. Journal of Shandong University: natural science 8(1): 243-256.

[14] Lindenmayer, D., Blanchard, W., Crane, M., Michael, D., Sato, C. (2018): Biodiversity benefits of vegetation restoration are undermined by livestock grazing. - Restoration Ecology 26(06): 1157-1164.

[15] Su, Y., Li, J., Qiu, J., Jin, Z., Fang, X., Chao, Y., Wang, J., Zhou, H. (2018): Current situation investigation and analysis of medicinal plant resources in Mount Tai area. Chinese Wild Plant Resources 37(5): 1006-9690.

[16] Tian, Z., Li, Z. (2012): The vertical distribution of vegetation patterns and its relationship with environment factors at the northern slope of Ili River Valley: a bimodal distribution pattern. - Acta Ecologica Sinica 32(4): 1151-1162.

[17] Togonidze, N., Akhalkatsi, M. (2015): Variability of plant species diversity during the natural restoration of the subalpine birch forest in the Central Great Caucasus. - Turkish Journal of Botany 39: 458-471.

[18] Wang, S., Loreau, M., Jordan, F. (2016): Biodiversity and ecosystem stability across scales in metacommunities. - Ecology Letters 19(5): 510-518.

[19] Wu, D., Jiao, W., Yu, W. (2017): Species composition and community characteristics of 15-year-old Robinia pseudoacacia forest and natural vegetation in Ansai, Shaanxi province. - Research of Soil and Water Conservation 24(4): 12-16.

[20] Xue, S., Zhu, F., Kong, X., Wu, C., Huang, L., Huang, N., Hartley, W. (2016): A review of the characterization and revegetation of bauxite residues (red mud). - Environmental Science \& Pollution Research 23(2): 1120-1132.

[21] Yu, D., Jiang, Y., Wang, Z., Zheng, C., Zhu, J., Wang, X., Shen, H., Fang, J., Tang, Z., He, J. (2009): Methods and protocols for plant community inventory. - Biodiversity Science 17(6): 533-548.

[22] Zheng, W., Zhu, J., Pan, C. (2008): Effect of tourism disturbance intensity on plant species diversity of meadow community in Kanasi Nature Reserve. - Acta Agrestia Sinica 16(6): 624-629, 635.

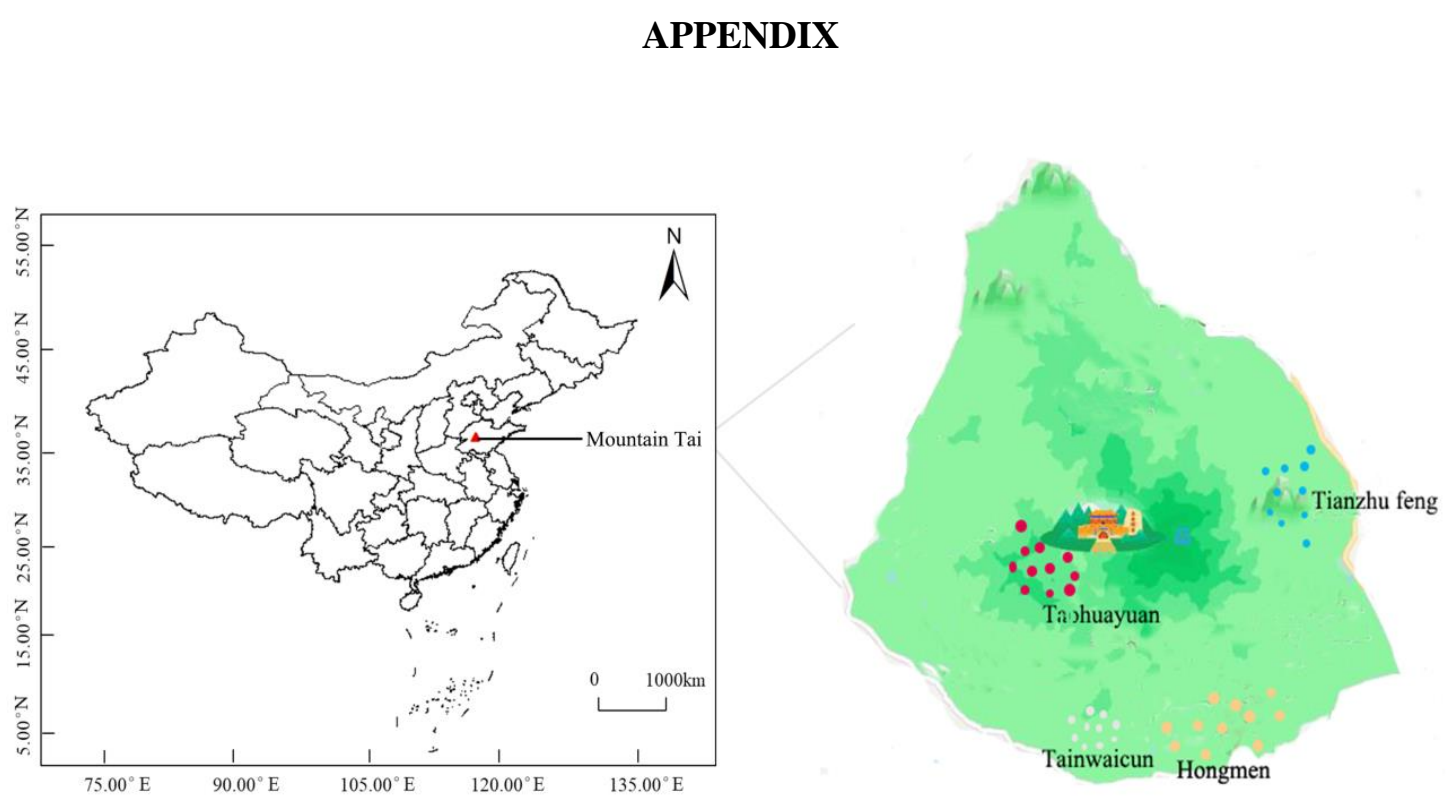

Figure S1. The map of the location of the sampling sites 
Table S1. Phenological differences between the studied species

\begin{tabular}{l|c|c|c}
\hline & Average DBH (cm) & Forest canopy density (\%) & Tree density (/ha) \\
\hline PT forest & 20.43 & 76 & 567 \\
PO forest & 11.63 & 73 & 1000 \\
RP forest & 15.03 & 81 & 733 \\
PD forest & 16.97 & 75 & 800 \\
LK forest & 18.33 & 92 & 1033 \\
PA forest & 19.42 & 86 & 900 \\
\hline
\end{tabular}

PT forest $=$ Pinus tabulaeformis forest, PO forest $=$ Platycladus orientalis forest, RP forest $=$ Robinia pseudoacacia forest, PD forest $=$ Pinus densiflora forest, LK forest $=$ Larix kaempferi forest PA forest $=$ Pinus armandii Franch. forest

Table S2. Species detected in the individual plots

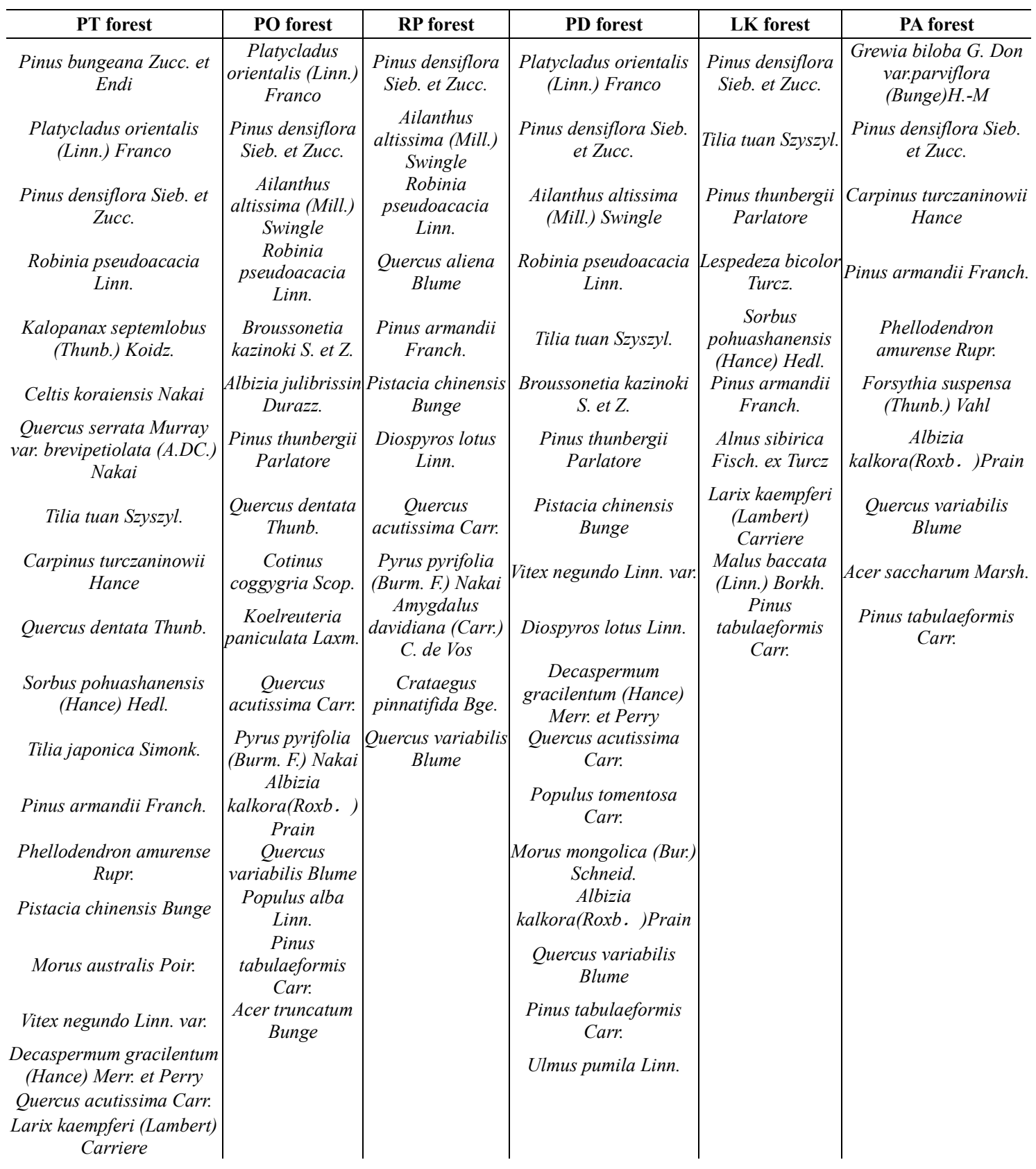




\begin{tabular}{c|c|c|c|c|c}
\hline PT forest & PO forest & RP forest & PD forest & LK forest & PA forest \\
\hline Albizia & & & & & \\
kalkora(Roxb.)Prain & & & & \\
Malus baccata (Linn.) \\
$\begin{array}{c}\text { Borkh } \\
\text { Crataegus pinnatifida Bge. }\end{array}$
\end{tabular}

APPLIED ECOLOGY AND ENVIRONMENTAL RESEARCH 19(6):4515-4526

http://www.aloki.hu • ISSN 15891623 (Print) • ISSN1785 0037 (Online)

DOI: http://dx.doi.org/10.15666/aeer/1906_45154526

(c) 2021, ALÖKI Kft., Budapest, Hungary 